\title{
MicroRNA-126-3p inhibits the proliferation, migration, invasion, and angiogenesis of triple-negative breast cancer cells by targeting RGS3
}

\author{
ZHIPENG HONG ${ }^{1-3 *}$, CHENGYE HONG $^{1 *}$, BO MA $^{4 *}$, QINGLAN WANG $^{1}$, \\ XI ZHANG ${ }^{1}$, LIANGQIANG LI ${ }^{1}$, CHUAN WANG ${ }^{2,3}$ and DEBO CHEN ${ }^{1}$ \\ ${ }^{1}$ Department of Breast Surgery, Affiliated Quanzhou First Hospital of Fujian Medical University, \\ Quanzhou, Fujian 362000; Departments of ${ }^{2}$ Breast Surgery and ${ }^{3}$ General Surgery, \\ The Affiliated Union Hospital of Fujian Medical University, Fuzhou, Fujian 350001; \\ ${ }^{4}$ Department of Breast Surgery, Zhejiang Hospital, Hangzhou, Zhejiang 310013, P.R. China
}

Received November 22, 2018; Accepted July 4, 2019

DOI: $10.3892 / o r .2019 .7251$

\begin{abstract}
Triple-negative breast cancer (TNBC) is characterized by fast progression with high potential for metastasis, and poor prognosis. The dysregulation of microRNAs (miRNAs) occurring in the initiation or progression of cancers often leads to aberrant gene expression. The aim of the present study was to explore the function of miR-126 in TNBC cells. Expression levels of miR-126-3p were determined by quantitative real-time PCR. Then, the effects of miR-126-3p on migration, proliferation, invasion, and angiogenesis were assessed through in vitro experiments including Cell Counting Kit-8, colony formation, Transwell invasion and vasculogenic mimicry formation assays. One of the target genes for miR-126-3p predicted by TargetScan was confirmed by luciferase activity assay. Results indicated that miR-126-3p expression was reduced in TNBC cell lines. Functional assays revealed that miR-126-3p overexpression inhibited cell proliferation, migration, invasion, colony formation capacity and vasculogenesis by 1.2-, 1.8-, 2.3-, 2.0- and 3.3-fold, respectively, compared to the miRNA-negative control group of MDA-MB-231 cells $(\mathrm{P}<0.001$, respectively). In addition, the regulator of $\mathrm{G}$-protein signaling 3 (RGS3) was hypothesized and validated as a direct
\end{abstract}

Correspondence to: Dr Chuan Wang, Department of Breast Surgery, The Affiliated Union Hospital of Fujian Medical University, Fuzhou, Fujian 350001, P.R. China

E-mail: chuanwang1968@outlook.com

Dr Debo Chen, Department of Breast Surgery, Affiliated Quanzhou First Hospital of Fujian Medical University, Quanzhou, Fujian 362000, P.R. China

E-mail: deboqz@163.com

*Contributed equally

Key words: microRNA-126-3p, triple-negative breast cancer, regulator of G-protein signaling 3, vasculogenic mimicry target of miR-126-3p in TNBC. The proliferation, migration, invasion, colony formation capacity and vasculogenesis of MDA-MB-231 cells were significantly increased by 1.4-, 2.0-, 1.8-, 1.4- and 3.2-fold, respectively, in cells transfected with pcDNA3.0-RGS3 compared to pcDNA3.0-negative control groups $(\mathrm{P}<0.001$, respectively). The influence of miR-126-3p expression was reversed by RGS3 restoration. Collectively, the present study revealed that miR-126-3p plays a role as a tumor suppressor in regulating TNBC cell activities by targeting RGS3, indicating that the miR-126-3p/RGS3 axis may be a potential treatment target.

\section{Introduction}

Breast cancer (BC) is the most commonly diagnosed, and the second most common cause of cancer-related deaths in women (1). There were 2.1 million new diagnoses of female BC cases worldwide in 2018, accounting for almost 1 in 4 cancer deaths (2). Triple-negative breast cancer (TNBC), one of the $\mathrm{BC}$ subtypes has been revealed to be immunonegative for estrogen receptor, progesterone receptor and human epidermal growth factor receptor-2. TNBC is a heterogeneous type of tumor characterized by several clinical features including its aggressive nature, higher rates of relapse and shorter overall survival in comparison with other subtypes of BC (3). In addition, TNBC more often metastasizes to the lungs, bone, liver, and brain than any other of the subtypes of BC (4-6). Although the biomarkers of human epidermal growth factor receptor 2, progesterone receptor and estrogen receptor have provided significant prognostic value for TNBC patients (7), development of new biomarkers is still necessary to obtain valuable information concerning diagnosis and treatment, and to further exploit effective therapeutic strategies and improve survival.

MicroRNAs (miRNAs), composed of 19-24 nucleotides, play crucial roles in a variety of biological processes, including cell proliferation, differentiation, migration, invasion, and apoptosis (8-10). Dysregulation of miRNA expression often appears in many cancers such as lung cancer, BC and cervical 
cancer, and is directly associated with tumor initiation, progression, and metastases (11-14). Human miR-126-3p is an endothelial-specific miRNA, encoding gene located in the intron of the EGFL7 gene at chromosome 9q34.3. This miRNA plays an important role during embryonic development and in angiogenesis (15). Previously it was revealed that the expression level of miR-126-3p in many aggressive tumors was significantly downregulated, such as osteosarcoma, colorectal cancer, prostate cancer as well as in other cancers (16-20), suggesting miR-126-3p to be a novel biomarker for cancer treatment.

Blood supply supports tumor growth and distant dissemination. It has caused the widespread concern of how angiogenesis occurs and functions, since vasculogenic mimicry (VM) was firstly demonstrated as a phenomenon of highly aggressive and metastatic melanoma cells forming highly patterned vascular channels in vitro in 1999. VM could be composed of a basement membrane in the absence of endothelial cells and fibroblasts (21), supported further by numerous underlying molecular pathway studies (22). Among these mechanisms, miRNAs may be involved. For example, vascular integrity may be affected by miR-126-3p, resulting in a disorganized tumor vasculature (23). Increasing evidence has indicated that the alternative microcirculation pathway was established by vasculogenic mimicry (VM) channels which exert a fatal effect in the early growth, metastasis and relapse of invasive BC (24-26). Hence, in the present study, the relationship between miR-126 and vascular mimicry was investigated, which may provide the theoretical basis for anti-vascular therapy in TNBC.

As a G-protein signaling regulator, regulator of G-protein signaling (RGS3) is characterized by a homologous sequence of a core RGS domain and switches off receptor-activated cellular signal transduction $(27,28)$. RGS3 is associated with tumor cell proliferation and migration $(29,30)$. In addition, ingenuity pathway analysis indicates that the RGS3 mRNA interacts with miR-126 (31,32). Previous studies further revealed that there is a direct 3 '-untranslated region binding site between RGS3 mRNA and miRNA-126, indicating that overexpressed RGS3 regulated by miRNA-126 through post-transcriptional modulation, is significantly associated with a poor prognosis of cancer patients (33).

Therefore, to explore new biomarkers for TNBC treatment, miR-126 expression in human MDA-MB-231 and HCC1937 cell lines was firstly investigated. Then, the effect of miR-126 expression on proliferation, migration, invasion, and angiogenesis of human TNBC was determined. Subsequently, RGS3 as the potential target gene of miR-126 was analyzed and validated by bioinformatics and luciferase activity assay. Finally, how miR-126-3p regulates target-gene expression was also investigated and the underlying mechanisms of TNBC progression were elucidated.

\section{Materials and methods}

Cell culture. The TNBC cell lines, MDA-MB-231 and HCC1937, and normal breast cell line MCF-10A were obtained from the Cell Resource Center of the Shanghai Institutes for Biological Sciences. The base medium used in the present study was L-15 Medium (cat. no. JCML1514500; Nalgene) for MDA-MB-231 cells, RPMI-1640 (Invitrogen;
Thermo Fisher Scientific, Inc.) for HCC1937 cells, and the complete growth medium was supplemented with $10 \%$ fetal bovine serum, $1 \%$ penicillin $(100 \mathrm{U} / \mathrm{ml})$ and $1 \%$ streptomycin $(100 \mathrm{U} / \mathrm{ml})$. MCF-10A cells were cultured in complete growth medium consisting of 1:1 mixture of Dulbecco's modified Eagle's medium and Ham's F12 medium supplemented with $5 \%$ (v/v) horse serum, $10 \mu \mathrm{g} / \mathrm{ml}$ insulin, $100 \mathrm{ng} / \mathrm{ml}$ cholera toxin, $20 \mathrm{ng} / \mathrm{ml}$ recombinant human epidermal growth factor, $0.5 \mu \mathrm{g} / \mathrm{ml}$ hydrocortisone and $1 \mathrm{unit} / \mathrm{ml}$ penicillin/streptomycin. The cells were all incubated in a humidified incubator at $37^{\circ} \mathrm{C}$ with $5 \% \mathrm{CO}_{2}$.

Cell transfection. miR-126-3p mimic, miR-126-3p inhibitor, negative control of miR-126-3p (miRNA-NC) which is defined as the cells transfected with the plasmids without miR-126-3p mimic or inhibitor, and RGS3-specific small interfering RNA (siRNA) were all synthesized by GenePharma Co., Ltd. According to the manufacturer's protocols, Lipofectamine 2000 (cat. no. 52887; Invitrogen; Thermo Fisher Scientific, Inc.) was used to transfect the synthesized miRNAs aforementioned or expression-ready RGS3 ORF construct and NC construct into the investigated MDA-MB-231 and HCC1937 cells. After $48 \mathrm{~h}$ of transfection, the cells were collected for the following experiments.

Cell counting kit-8 (CCK-8) assay. Cell proliferation was assessed by a Cell Counting Kit- 8 (Dojindo Molecular Technologies). Cells were seeded at a density of $1 \times 10^{5}$ cells/well to a 96-well plate. Forty-eight hours after transfection, CCK-8 fluids were added to the cells with a final concentration of $10 \%$ and maintained at $37^{\circ} \mathrm{C}$ for $4 \mathrm{~h}$. The optical density was assessed at $450 \mathrm{~nm}$ using a Microplate Reader (Bio-Rad Laboratories, Inc.).

Migration and invasion assays. The Transwell assay kit (product no. 356234; Corning Incorporated) was used to evaluate the invasion of the transfected cells. These cells supplemented with DMEM were seeded to the upper chamber. DMEM supplemented with FBS was added to the lower chamber. The cells were maintained at $37^{\circ} \mathrm{C}$ for $48 \mathrm{~h}$ and were then fixed by methanol. Non-migrated cells on the upper surface of the membrane were removed by a cotton swab. The migrated cells on the lower side of the membrane were stained using $0.1 \%$ crystal violet for $5 \mathrm{~min}$ at room temperature, and imaged. ImageJ v1.52 software (National Institutes of Health) was used to count the number of invading cells. The invasion assay was performed in accordance with migration assay except that the Transwell membrane was pre-coated with Matrigel (BD Biosciences).

Colony formation. Cells transfected with synthetic miRNAs were seeded to a 6 -well plate at a density of 500 cells/well and incubated in DMEM with $10 \% \mathrm{FBS}$ at $37^{\circ} \mathrm{C}$ for 2 weeks. Then, the cells were fixed with methanol, washed with PBS and then stained with $0.1 \%$ crystal violet solution (Beyotime Institute of Biotechnology). The number of colonies with $>50$ cells were counted.

$V M$ formation assays. To assess the effect of miR-126-3p and RGS3 on the VM of TNBC cells, $2 \times 10^{4}$ transfected cells 
overexpressing plasmid or a control Matrigel $(100 \mu \mathrm{l})$ were placed on a 48 -well plate, and incubated at $37^{\circ} \mathrm{C}$. The number of tubes (complete circular structures) in each well were captured and counted using an inverted microscope (Nikon Corp.). The three readings of each well were averaged to be the final reading.

Quantitative real-time PCR ( $q R T-P C R)$. Total RNA was extracted from the cultured cells using Trizol reagent (Invitrogen; Thermo Fisher Scientific, Inc.) and quantified using Ultra-micro UV analyzer Q6000UV (Quawell Technology, Inc.). The sequence of stem-loop structures used in the present study was: 5'-CTCAACTGGTGTCGTGGA GTCGGCAATTCAGTTGAGCGCATTAT-3'. The sequence of microRNA-126-3p was 5'-CGTACCGTGAGTA $\underline{\text { ATAAT }}$ GCG-3'. The underlined part was the combined part of the stem-loop and target sequence. Thus, the first cDNA strand specific to miRNA-126-3p was synthesized from total RNA using Bestar $^{\mathrm{TM}}$ qPCR RT Kit (cat. no. 2220; DBI Bioscience) on a PCR Amplifier (Product no. K960; Hangzhou Jingge Scientific Instrument Co., Ltd.). Real-time PCR was conducted using Stratagene Mx3000P (Agilent Technologies, Inc.) and by applying Bestar ${ }^{\mathrm{TM}}$ qPCR Master Mix (cat. no. 2043; DBI Bioscience). U6 snRNA was used as an endogenous control and analyzed with the $2^{-\Delta \Delta \mathrm{Cq}}$ method (34). The primers are listed in Table I.

Dual luciferase activity assay. The targets of miR-126-3p were predicted by bioinformatics analysis using algorithm TargetScan (http://www.targetscan.org/vert_72/), and the TargetScan score was investigated for has-miR-126-3p binding to RGS3 in miRDB (http://mirdb.org/cgi-bin/search. cgi). Then, the wild 3'UTR fragment of RGS3 carrying the putative miR-126-binding site was amplified and sub-cloned into the psiCHECK-2 vector (Bioneer Co., Ltd.) to construct pMiR-wild-type (pMiR-WT). The isolated plasmid was sequenced and mutated using Directed Mutagenesis System (Invitrogen; Thermo Fisher scientific, Inc.), to produce pMiR-mutant-plasmid (pMiR-Mut) with seven point mutations: CTGCCC C(CtoA) G(GtoT) G(GtoA) T(TtoC) A(AtoT) $\mathrm{C}(\mathrm{CtoG}) \mathrm{G}(\mathrm{GtoA})$ AGGGGGC. The sites of the mutation in RGS3 sequence are $\mathrm{C}$ in $152438, \mathrm{G}$ in $152439, \mathrm{G}$ in 152440 , $\mathrm{T}$ in 152441, $\mathrm{A}$ in $152442, \mathrm{C}$ in 152443 and $\mathrm{G}$ in 152444 , which is based on the sequence provided in the NCBI GenBank (https://www.ncbi.nlm.nih.gov/nuccore/NG_02951 2.1 from $=4999 \&$ to $=158013 \&$ report=genbank). Sunsequently, the manufacturer's instructions were followed and Lipofectamine 2000 (cat. no. 52887; Invitrogen; Thermo fisher Scientific, Inc.) was used to transfect plasmids containing the 3'UTR fragment (pMiR-WT) or mutant (pMiR-Mut) respectively into MDB-MA-231 and HCC1937 cells to express miRNA-NC or pcDNA3.0-NC or miR-126-3p mimic. Forty-eight hours after transfection, the cells were lysed and a reporter assay was performed using the Dual-luciferase assay system (Promega Corp.).

Statistical analysis. All the experiments were repeated three times. The results were expressed as the mean \pm standard deviation (SD). A Student's t-test was used to analyze the differences between two groups. One-way analysis of variance
Table I. Primer sequences used in RT-qPCR.

\begin{tabular}{ll}
\hline Item & \multicolumn{1}{c}{ Sequences (5'-3') } \\
\hline GAPDH F & TGTTCGTCATGGGTGTGAAC \\
GAPDH R & ATGGCATGGACTGTGGTCAT \\
U6 F & CTCGCTTCGGCAGCACA \\
U6 R & AACGCTTCACGAATTTGCGT \\
All R & CTCAACTGGTGTCGTGGA \\
hsa-miR-126-3p RT & CTCAACTGGTGTCGTGGAGTCG \\
& GCAATTCAGTTGAGCGCATTAT \\
hsa-miR-126-3p F & ACACTCCAGCTGGGTCGTACCG \\
& TGAGTAATAA \\
miR-126-3p NC & CAGUACUUUUGUGUAGUACAA \\
miR-126-3p mimic & UCGUACCGUGAGUAAUAAUGCG \\
miR-126-3p inhibitor & CGCAUUAUUACUCACGGUACGA \\
RGS3 F & TCAGAGGAAGCCCTCAAGTG \\
RGS3 R & TGGATGCCATCTTGGACTGT \\
\end{tabular}

F, forward; R, reverse; RGS3, regulator of G-protein signaling 3.

and Tukey's post hoc test were used to analyze the differences among three or more groups. GraphPad Prism 6 (GraphPad Software, Inc.) was used for data analysis. $\mathrm{P}<0.05$ was considered to indicate a statistically significant difference.

\section{Results}

Overexpression of miR-126-3p inhibits proliferation, migration, invasion, and angiogenesis of TNBC cell lines whereas silencing of $m i R-126-3 p$ promotes these processes. The endogenous expression of miR-126-3p in MCF-10A, MDA-MB-231 and HCC1937 cells are presented in Fig. 1A, indicating that the expression of miR-126-3p in TNBC cells was significantly lower than that in normal breast cells $(\mathrm{P}<0.001$, respectively). To investigate the effect of miR-126-3p on human TNBC cells, the MDA-MB-231 and HCC1937 cells were transfected with miR-126-3p mimic or miR-126-3p inhibitor. Non-transfected cells were used as the control group and cells transfected with miRNA-NC were used as the negative control. The expression of miR-126-3p in the miR-126-3p mimic group was increased by 2.2-fold in MDA-MB-231 cells and 2.4-fold in HCC1937 cells, respectively, compared with that in the miRNA-NC groups $(\mathrm{P}<0.001)$. The expression level of miR-126-3p in miR-126-3p inhibitor group was decreased by 2.3 -fold in MDA-MB-231 cells and 3.8-fold in HCC1937 cells respectively compared with that in miRNA-NC group $(\mathrm{P}<0.001)$, indicating that overexpressing or silencing of miR-126-3p were achieved by transfection of miR-126-3p mimic or inhibitor respectively (Fig. 1A). The viability of MDA-MB-231 and HCC1937 cells was significantly increased at the 72-h time-point by miR-126-3p inhibition compared with that in the miRNA-NC group $(2.47 \pm 0.09$ vs. $1.57 \pm 0.03$ in MDA-MB-231 cells and $3.66 \pm 0.05$ vs. $2.81 \pm 0.05$ in $\mathrm{HCC} 1937$ cells, $\mathrm{P}<0.001$, normalized to levels at $24 \mathrm{~h}$, respectively), and was decreased at the 72-h time-point by miR-126-3p overexpression compared with that in the miRNA-NC group $(1.28 \pm 0.05$ vs. $1.57 \pm 0.03$ in 
A

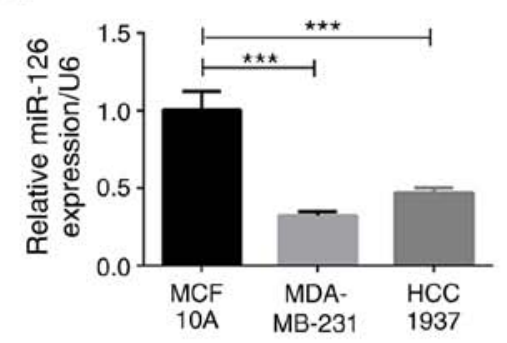

MDA-MB-231

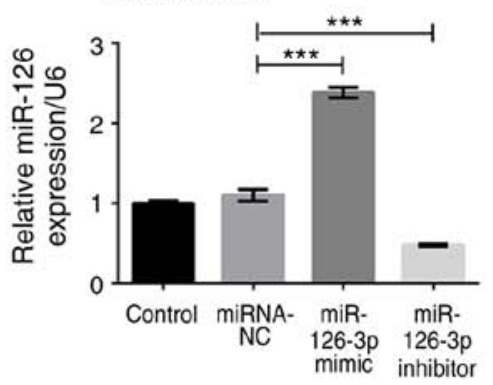

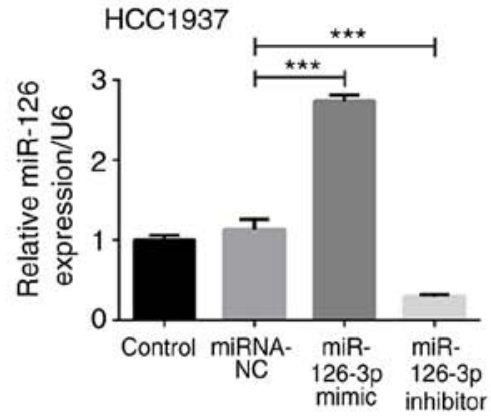

C
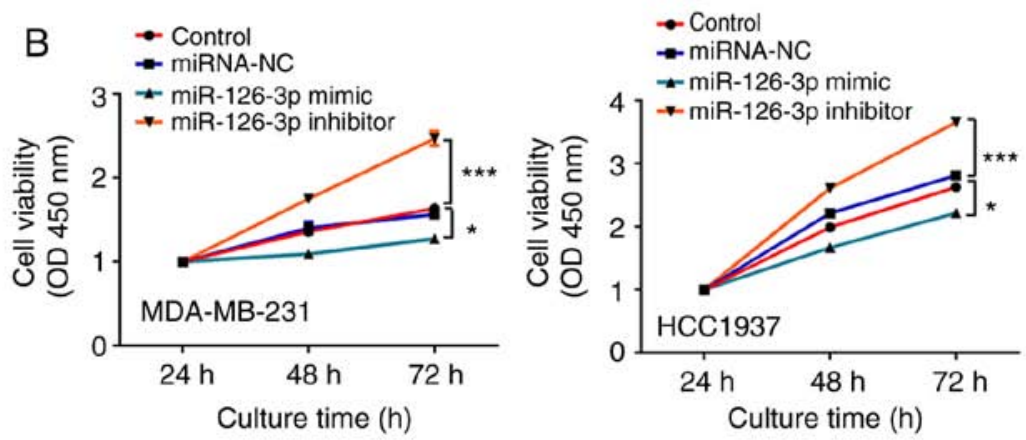

Migration
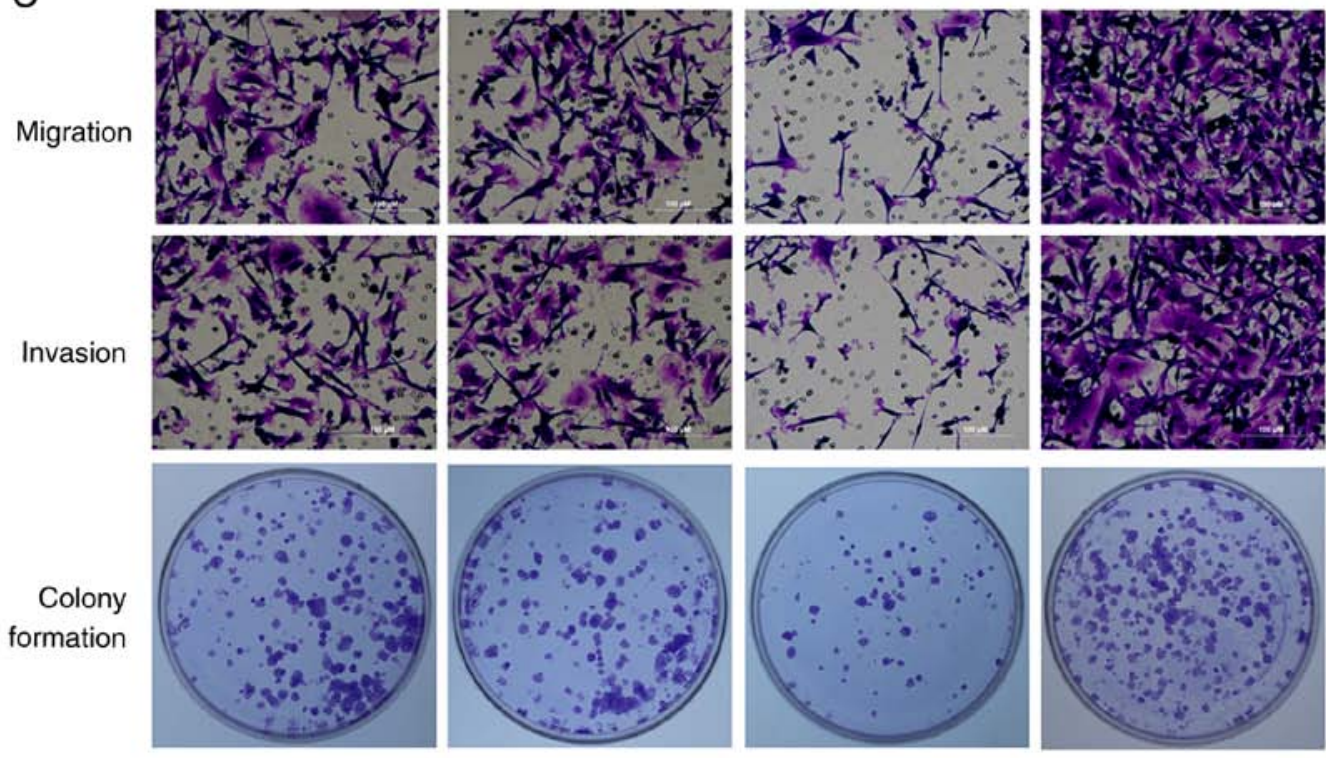

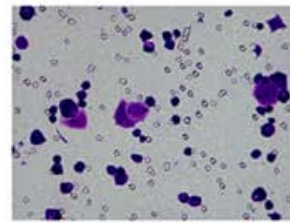

Control

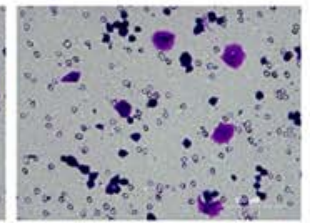

miRNA-NC

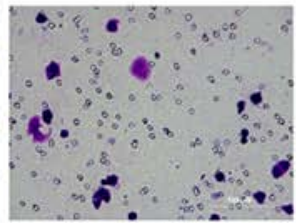

miR-1263p mimic
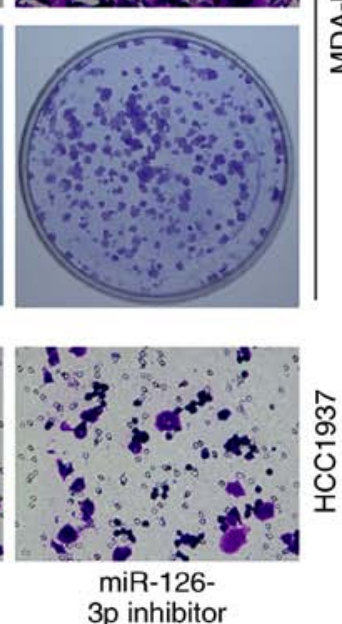

Figure 1. miR-126-3p regulates MDA-MB-231 and HCC1937 cell activities. (A) The expression of miR-126 in MCF-10A, MDA-MB-231, HCC1937 cell lines, and in the control, miRNA-NC, miR-126 mimic and miR-126 inhibitor groups of MDA-MB-231 and HCC1937 cells were assessed by qRT-PCR. (B) The cell proliferation in MDA-MB-231 and HCC1937 cell lines. (C) Images of cell migration, invasion, and colony formation in MDA-MB-231 and HCC1937 cell lines. Data presented were the averaged mean of at least three independent experiments. Error bars indicate the standard deviation. ${ }^{*} \mathrm{P}<0.05$, and ${ }^{* * *} \mathrm{P}<0.001$.

MDA-MB-231 cells and $2.22 \pm 0.06$ vs. $2.81 \pm 0.05$ in $\mathrm{HCC} 1937$ cells, $\mathrm{P}<0.05$, normalized to levels at $24 \mathrm{~h}$, respectively, Fig. 1B). The migration of MDA-MB-231 and HCC1937 cells was significantly enhanced by miR-126-3p inhibition compared with that in the miRNA-NC group $(138.33 \pm 1.53$ vs. $68 \pm 6.56$ in MDA-MB-231 cells and $81.67 \pm 1.53$ vs. $40.33 \pm 2.52$ in HCC1937 cells, $\mathrm{P}<0.001$, respectively), and was reduced by miR-126-3p overexpression compared with that in the miRNA-NC group (37.33 \pm 4.04 vs. $68 \pm 6.56$ in MDA-MB-231 cells and $14.33 \pm 1.53$ vs. $40.33 \pm 2.52$ in $\mathrm{HCC} 1937$ cells, $\mathrm{P}<0.001$, respectively, Fig. 1C and D). Similarly, MDA-MB-231 cell invasion was significantly enhanced by silencing of miR-126-3p compared 

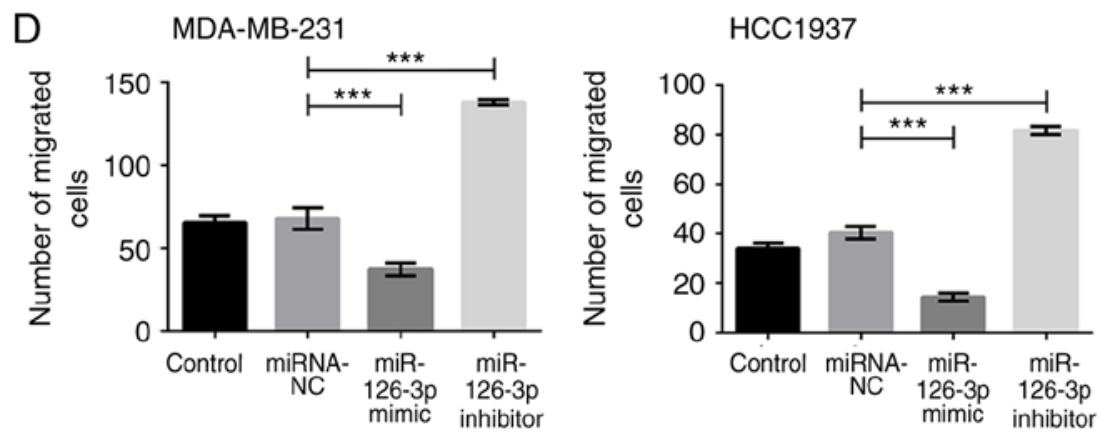

E

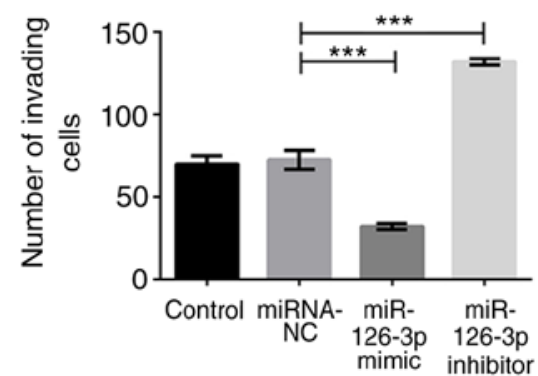

F

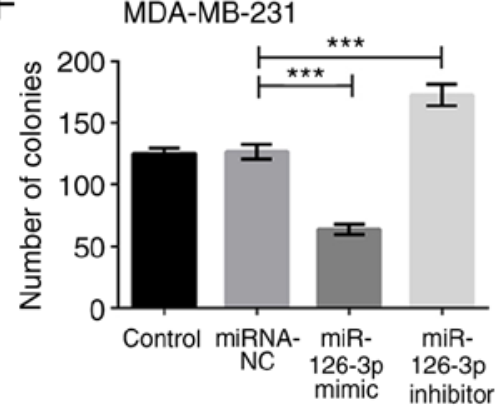

H MDA-MB-231

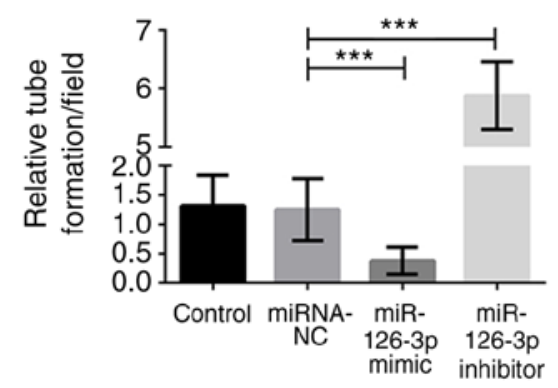

G

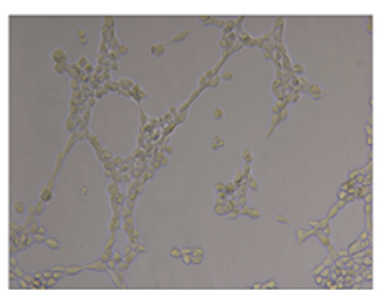

Control

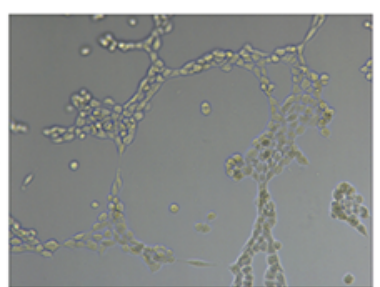

miRNA-NC

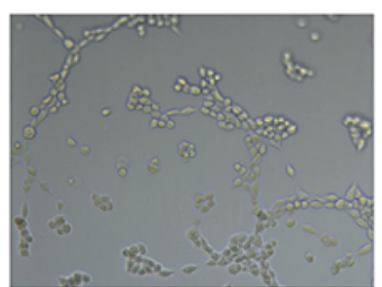

miR-126-3p

mimic

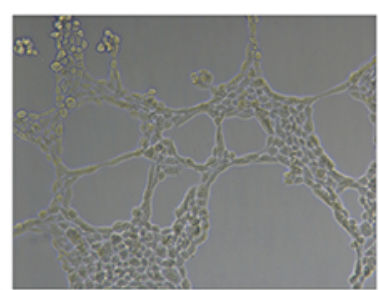

miR-126-3p

inhibitor

Figure 1. Continued. miR-126-3p regulates MDA-MB-231 and HCC1937 cell activities. (D) The cell migration in MDA-MB-231 and HCC1937 cell lines. (E) The cell invasion in the MDA-MB-231 cell line. (F) The colony formation number in the MDA-MB-231 cell line. (G) The VM in the control, miRNA-NC, miR-126 mimic, and miR-126 inhibitor groups of MDA-MB-231 cells are presented (magnification, $\mathrm{x} 100)$. (H) The relative tube formation in the MDA-MB-231 cell line were assessed after miRNA transfection. Data presented were the averaged mean of at least three independent experiments. Error bars indicate the standard deviation. ${ }^{*} \mathrm{P}<0.05$, and ${ }^{* * *} \mathrm{P}<0.001$. VM, vasculogenic mimicry.

with that in the miRNA-NC group $(132 \pm 2$ vs. $72.67 \pm 5.69$, $\mathrm{P}<0.001)$, and was decreased by overexpression of miR-126-3p compared with that in the miRNA-NC group $(32 \pm 1.73$ vs. $72.67 \pm 5.69, \mathrm{P}<0.001$, Fig. $1 \mathrm{C}$ and $\mathrm{E})$. The number of colonies exhibited a $50 \%$ reduction in MDA-MB-231 cells overexpressing miR-126-3p and a 36\% enhancement in MDA-MB-231 cells with miR-126-3p silencing when compared to those in the miRNA-NC respectively $(63.67 \pm 4.04$ and $172.67 \pm 8.50$ vs. $126.67 \pm 5.86, \mathrm{P}<0.001$, respectively, Fig. $1 \mathrm{C}$ and F). The VM assay revealed that tube formation was reduced $70 \%$ in the group of MDA-MB-231 cells overexpressing miR-126-3p when compared to that in the miRNA-NC group $(\mathrm{P}<0.001)$ while it was increased 3.7-fold in MDA-MB-231 cells with miR-126-3p silencing when compared to the miRNA-NC group $(\mathrm{P}<0.001)$ (Fig. $1 \mathrm{G}$ and $\mathrm{H}$ ), indicating that tube formation capacity was inhibited by the miR-126-3p mimic and enhanced by the miR-126-3p inhibitor. There was no difference between the control group and miRNA-NC group in terms of cell viability, migration, invasion, colony formation, and tube formation.

$R G S 3$ is a target gene ofmiR-126-3p. The TargetScan algorithm predicted that miR-126-3p binded to 3'UTR of RGS3, and the
TargetScan score was 67 for has-miR-126-3p binding to RGS3 in miRDB. The DNA sequencing result of pRGS3-Mut finally confirmed the same mutation sites as human pRGS3-WT from the GenBank sequence, which validated the recombinant pcDNA3.0-RGS3 plasmid. Therefore, the pRGS3-WT or pRGS3-Mut with mimic control or miR-126-3p mimic were co-transfected into MDA-MB-231 and HCC1937 cells, and luciferase activity was detected. Luciferase activity in cells transfected with pRGS3-WT and miR-126-3p mimic was reduced 2.2-fold compared with that in cells transfected with pRGS3-WT and mimic control $(\mathrm{P}<0.001)$ (Fig. S1), however, the difference between co-transfection with pRGS3-Mut and the miR-126-3p mimic was not significant.

Ectopic expression of RGS3 affects cell proliferation, migration, invasion, and angiogenesis. The endogenous expression of RGS3 in MCF-10A, MDA-MB-231 and HCC1937 cells presented in Fig. 2A, revealed that the expression of RGS3 in TNBC cells was significantly higher than that in normal breast cells ( $\mathrm{P}<0.001$, respectively). pcDNA3.0-NC, pcDNA3.0-RGS3 alone or accompanied by si-RGS3 were respectively transfected into MDA-MB-231 and HCC1937 cells. Non-transfected cells 
A

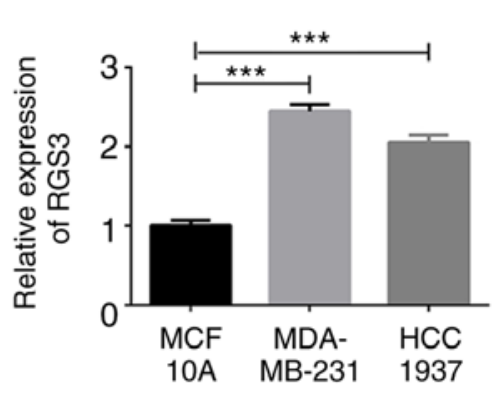

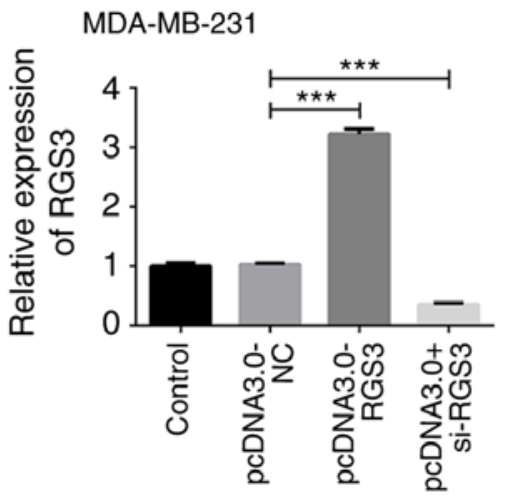

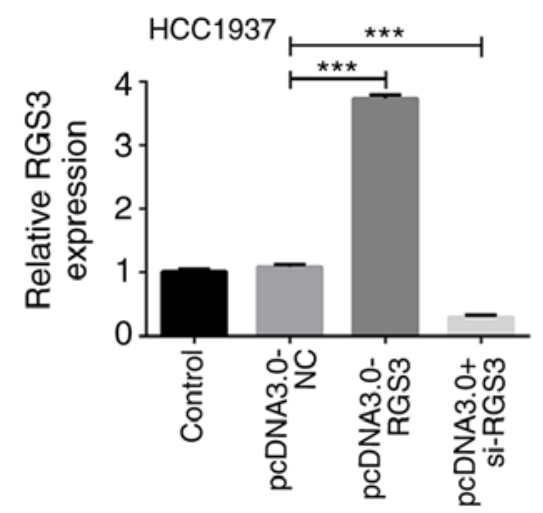

B

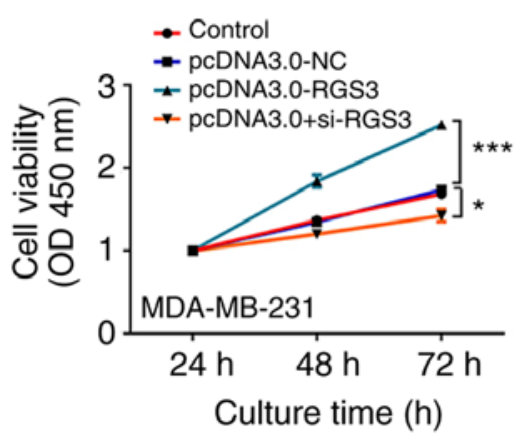

C
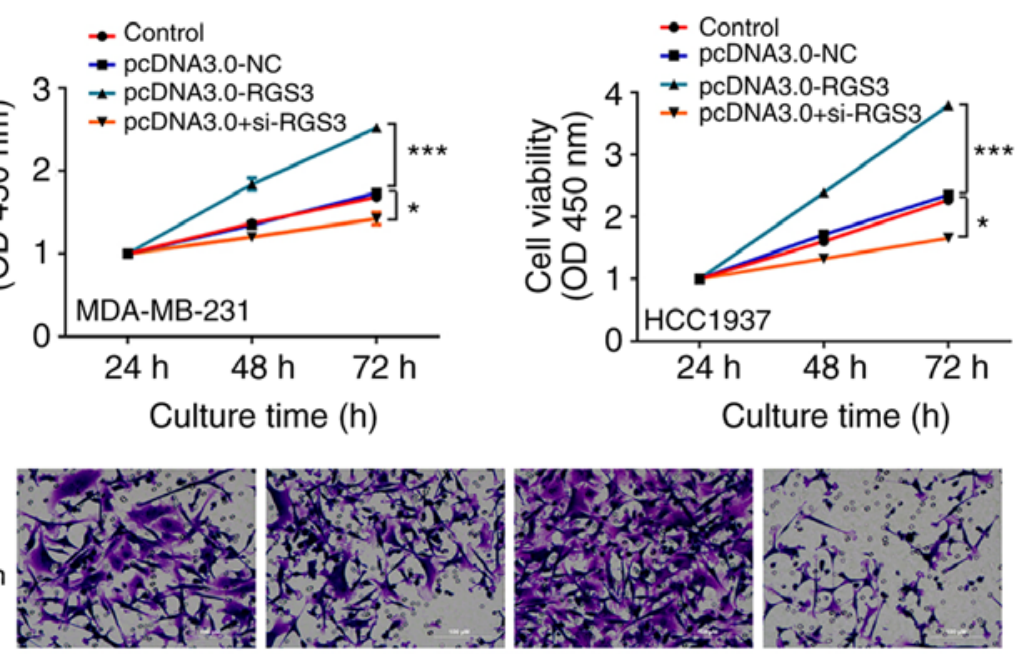

Migration

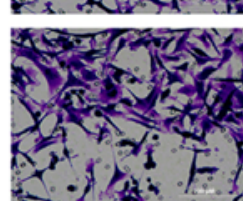

Invasion

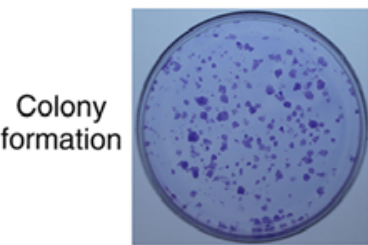

Control
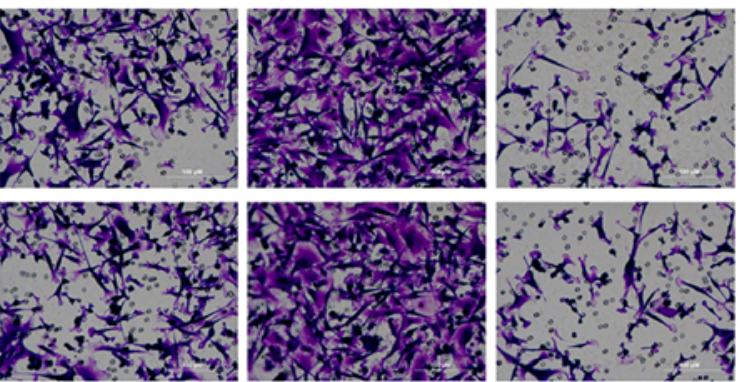

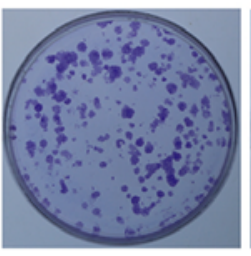

pcDNA3.0-NC

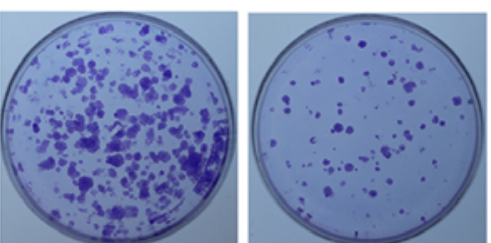

pcDNA3.0-RGS3 pcDNA3.0+si-RGS3

Figure 2. Ectopic expression of RGS3 affects miR-126-induced regulation of MDA-MB-231 cells activities. (A) The expression of RGS in MCF-10A, MDA-MB-231, HCC1937 cell lines, and in the control, miRNA-NC, miR-126 mimic and miR-126 inhibitor groups of MDA-MB-231 and HCC1937 cells were assessed by qRT-PCR. (B) The cell proliferation in MDA-MB-231 and HCC1937 cell lines. (C) Images of cell migration, invasion, and colony formation in the MDA-MB-231 cell line. Data presented were the averaged mean of at least three independent experiments. Error bars indicate the standard deviation. ${ }^{*} \mathrm{P}<0.05$ and ${ }^{* * *} \mathrm{P}<0.001$.

were used as the control group. The expression of RGS3 in the pcDNA3.0-RGS3 group was increased by 3.1-fold in MDA-MB-231 cells and 3.4-fold in HCC1937 cells compared with that in the pcDNA3.0-NC groups $(\mathrm{P}<0.001$, respectively). The expression level of RGS3 in the pcDNA3.0+si-RGS3 group was decreased by 2.8 -fold in MDA-MB-231 cells and 3.6-fold in HCC1937 cells compared with that in the pcDNA3.0-NC group $(\mathrm{P}<0.001$, respectively), indicating that overexpression or silencing of RGS3 were achieved by transfection of pcDNA3.0-RGS3 or pcDNA3.0+si-RGS3, respectively (Fig. 2A). The viability of MDA-MB-231 cells and HCC1937 cells was significanlty increased at the 72-h time-point in the transfected pcDNA3.0-RGS3 group compared with that in the pcDNA3.0-NC group $(2.52 \pm 0.05$ vs. $1.74 \pm 0.05$ in MDA-MB-231 cells and $3.80 \pm 0.03$ vs. $2.35 \pm 0.04$ in HCC1937 cells, $\mathrm{P}<0.001$, normalized to levels at $24 \mathrm{~h}$, respectively), and was decreased at the 72-h time-point in the transfected pcDNA3.0+si-RGS3 group compared with that in the pcDNA3.0-NC group $(1.42 \pm 0.07$ vs. $1.74 \pm 0.05$ in MDA-MB-231 cells and $1.66 \pm 0.05$ vs. $2.35 \pm 0.04$ in HCC1937 cells, $\mathrm{P}<0.05$, normalized to levels at $24 \mathrm{~h}$, respectively, Fig. $2 \mathrm{~B}$ ). In Fig. 2C-E, migration, and invasion of the MDA-MB-231 cell transfected by pcDNA3.0-RGS3 were enhanced compared with those in the pcDNA3.0-NC group (100 and 77\% increase in 

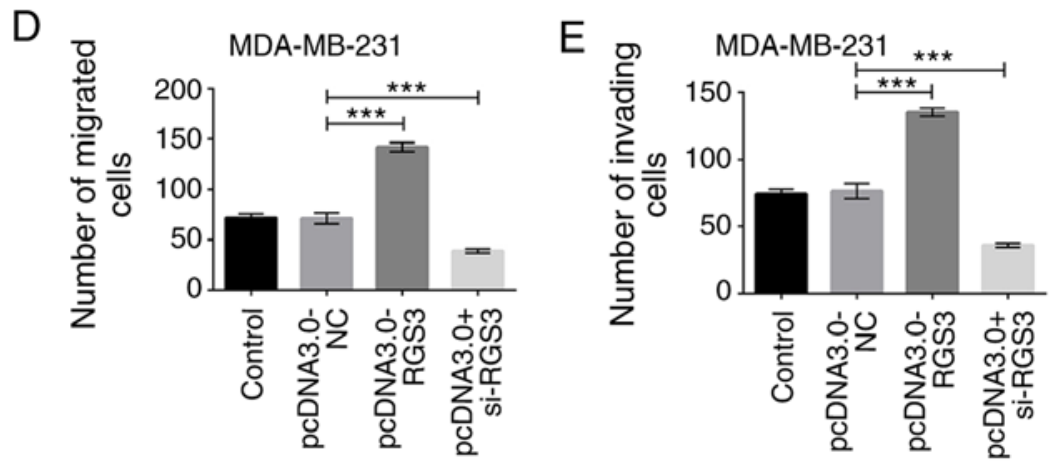

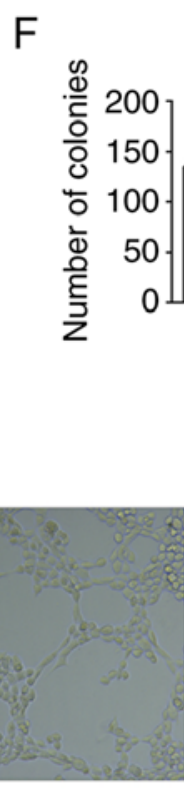

Control

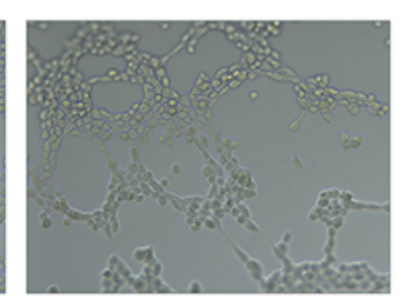

pcDNA3.0-NC
$\mathrm{H}$

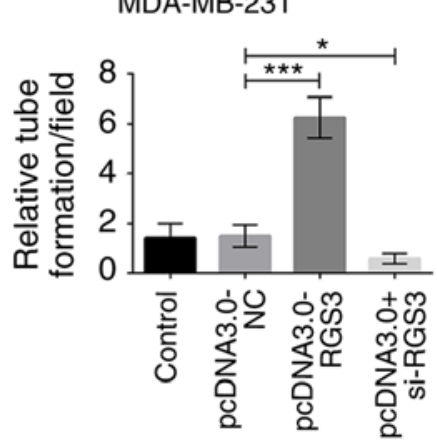

$\mathrm{G}$

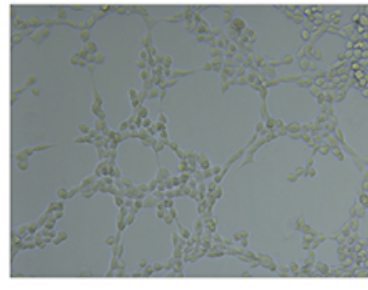

Figure 2. Continued. Ectopic expression of RGS3 affects miR-126-induced regulation of MDA-MB-231 cells activities. (D) The cell migration, (E) the cel invasion, (F) the colony formation number, in the control, pcDNA3.0-NC, pcDNA3.0-RGS3, and pcDNA3.0+si-RGS3 groups of MDA-MB-231 cells are presented. (G) The VM in the control, pcDNA3.0-NC, pcDNA3.0-RGS3, and pcDNA3.0+si-RGS3 groups of MDA-MB-231 cells are presented (magnification, $\mathrm{x} 100)$. (H) The relative tube formation in the MDA-MB-231 cell line transfected with pcDNA3.0-NC, pcDNA3.0-RGS3 alone or combined with RGS3-specific si-RGS3 were assessed. ${ }^{*} \mathrm{P}<0.05$ and ${ }^{* * *} \mathrm{P}<0.001$. RGS3, regulator of G-protein signaling 3; VM, vasculogenic mimicry.

cell migration and invasion, respectively; $\mathrm{P}<0.001)$. In addition, MDA-MB-231 cell migration and invasion were attenuated by pcDNA3.0+si-RGS3 in comparison with the pcDNA3.0-NC group (45\% and $52 \%$ decline in cell migration and invasion, respectively; $\mathrm{P}<0.001)$. The number of colonies presented a $37 \%$ increase in the pcDNA3.0-RGS3 MDA-MB-231 cells and a $44 \%$ abatement in the pcDNA3.0+si-RGS3 MDA-MB-231 cells when compared to pcDNA3.0-NC respectively $(\mathrm{P}<0.001$, Fig. 2C and F). Tube formation presented in the VM assay was increased 3.2-fold in the pcDNA3.0-RGS3 MDA-MB-231 cells when compared to that in the pcDNA3.0-NC group $(\mathrm{P}<0.001)$, while it was reduced $61 \%$ in the si-RGS3 MDA-MB-231 cells when compared to the pcDNA3.0-NC group $(\mathrm{P}<0.05)$ (Fig. 2G and H). There was no difference between the control group and the pcDNA3.0-NC group regarding cell viability, migration, invasion, colony formation, and tube formation.

Restoration of RGS3 reverses the inhibitory effects of miR-126-3p in TNBC cells. Two groups of miR-126-3p mimic alone or with pcDNA3.0-RGS3 were set up to further validate whether the restoration of RGS3 can reverse the inhibitory effects of miR-126-3p in TNBC cells. Results in Fig. 3A-D revealed that the viability, migration, and invasion of MDA-MB-231 cells were all increased by 1.5 - (at the 72-h, time-point normalized to the levels at $24 \mathrm{~h}$ ), 3.0- and 3.2-fold respectively by co-transfection of miR-126-3p mimic and pcDNA3.0-RGS3 compared with cells only transfected with miR-126-3p mimic $(\mathrm{P}<0.001)$. Similarly, the viability and migration of HCC1937 cells were all increased by 1.4- (at the 72-h time-point, normalized to levels at $24 \mathrm{~h}$ ) and 3.3-fold respectively by co-transfection of miR-126-3p mimic and pcDNA3.0-RGS3 compared with cells only transfected with miR-126-3p mimic $(\mathrm{P}<0.001)$. Moreover, there was a 1.5-fold enhancement of the number of colonies in MDA-MB-231 cells co-transfected with miR-126-3p mimic and pcDNA3.0-RGS3 when compared to that in the cells transfected with the miR-126-3p mimic $(\mathrm{P}<0.001$, Fig. 3B and $\mathrm{E}$ ). In the $\mathrm{VM}$ assay, tube formation was increased by 6.5-fold in the MDA-MB-231 cells co-transfected with the miR-126-3p mimic and pcDNA3.0-RGS3 compared with that in the cells transfected with the miR-126-3p mimic $(P<0.001$, Fig. 3F-G). 

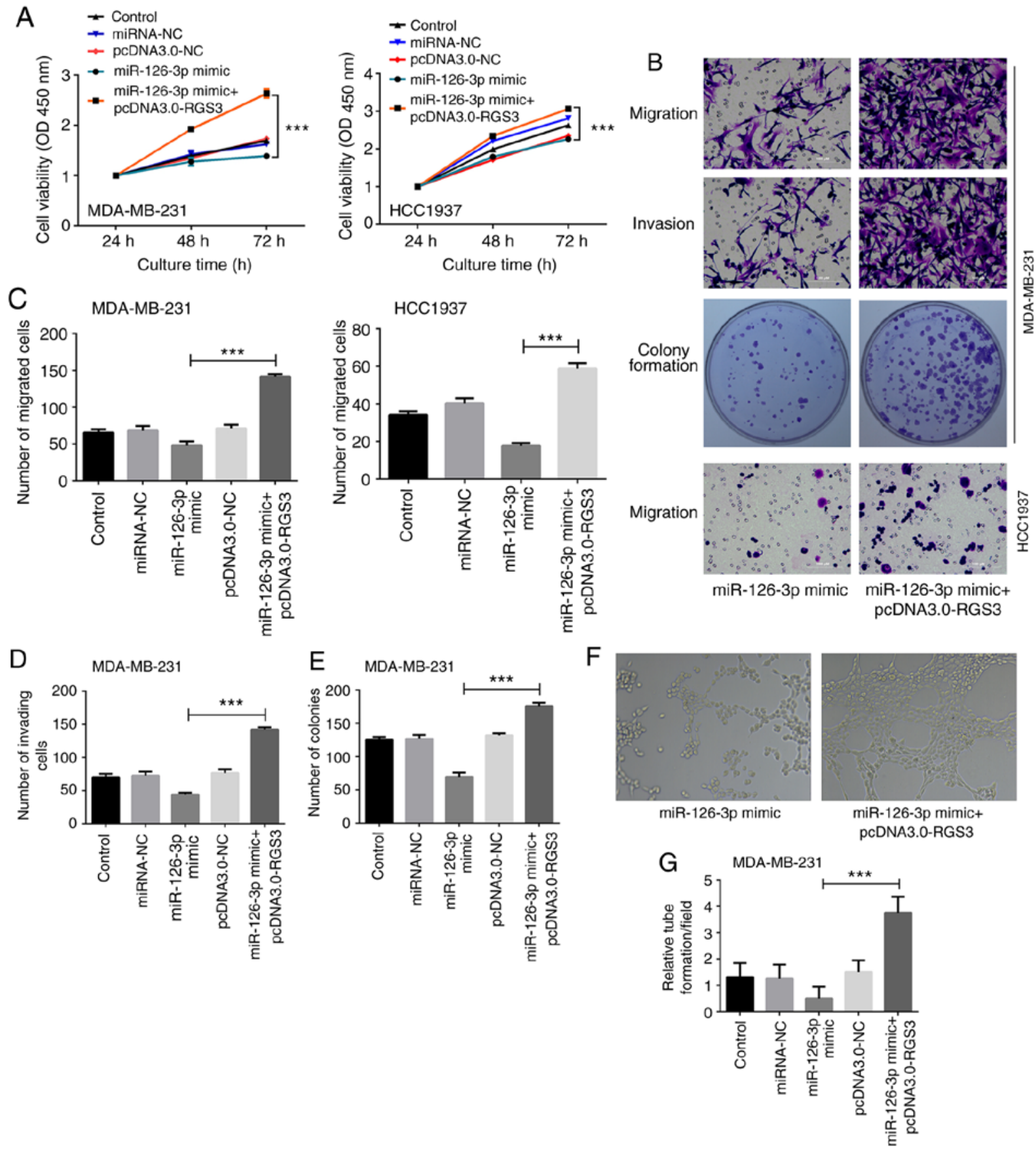

Figure 3. Overexpression of RGS3 reverses the inhibitory effect of miR-126-3p in TNBC cells. (A) The cell proliferation and (C) the cell migration in MDA-MB-231 and HCC1937 cell lines, (D) the cell invasion, (E) the colony formation number and (G) the tube formation in the MDA-MB-231 cell line transfected with RGS3 construct and/or miR-126-3p mimic were assessed. Data presented were the averaged mean of at least three independent experiments. Error bars indicate the standard deviation. ${ }^{* * *} \mathrm{P}<0.001$. (B) Images of cell migration, invasion and colony formation, and (F) the VM in the miR-126-3p mimic and miR-126-3p mimic+pcDNA3.0-RGS3 groups of the MDA-MB-231 cell line are presented (magnification, x100). RGS3, regulator of G-protein signaling 3; TNBC, triple-negative breast cancer; VM, vasculogenic mimicry.

\section{Discussion}

Increasing evidence has revealed that specific microRNA clusters may play an important role in the biology of TNBC, and may be of clinical relevance in TNBC, knowledge which should assist disease prognostication and therapy (35). The present study revealed that miR-126-3p was decreased in TNBC cells and miR-126-3p overexpression inhibited cell proliferation, migration, and invasion. RGS3 was predicted to be a target gene of miR-126-3p by the TargetScan algorithm and validated by luciferase activity assay. Furthermore, RGS3 silencing reversed the effect of miR-126-3p knockdown. Finally, it was determined that miR-126-3p knockdown activated VM, which could be reversed by silencing of RGS3.

Multiple miRNAs are associated with the metastasis and prognosis of BC (36-39). For instance, overexpression of miR-30c-2-3p inhibited the migration and invasion of BC cells, while low or underexpression of miR-30c-2-3p was correlated with poor overall survival (40). An increasing number of studies has confirmed that miRNA expression profiles are dysregu- 
lated in TNBC patients compared to healthy controls. For example, miR-190a, miR-136-5p, miR-126-5p, miR-135b-5p and miR-182-5p may be associated with the development and progression of TNBC (41). Although miR-126-3p has been reported as an oncogenic miRNA, promoting proliferation in gastric cancer cells (42), it has also been revealed to be a tumor suppressor due to its inhibition in the growth of colon cancer cell lines, HEK 293 and MCF-7 cells by targeting p85b and IRS-1, respectively $(43,44)$. However, in a study of miRNA expression profiles of 24 triple-negative breast cancers and 14 adjacent normal tissues using deep sequencing technology, miR-126-3p was revealed to be significantly downregulated $(\mathrm{P}<0.05$; fold change 1.8-2.6) in TNBC (45). Additionally, restoring miR-126-3p in MDA-MB-231 cells reduced cell proliferation and the levels of miR-126-3p in tumor tissues predicted TNBC outcomes (46). Novel prognostic and predictive miRNA targets of TNBC, include a miRNA signature that predicts patient response to anthracycline-based chemotherapy, which may improve clinical management and/or lead to the development of novel therapies (47). Notably, it was surmised that miR-126-3p acts as a tumor-suppressor miRNA in TNBC cancer cells in the present study, which further extends the current knowledge of microRNA regulatory characteristics and network in TNBC.

Notably, previous results indicated that a combination treatment with miRNAs, in particular miR-126-3p, enhanced the activity of specific $\mathrm{BC}$ drugs in vitro, even in the most aggressive BC subtype, TNBC (48). In addition, whole transcriptome studies, coupled with Gene Ontology and pathway analysis revealed a notable landscape for miR-126-3p activity in $\mathrm{BC}$, such as involvement in cell cycle regulation of $\mathrm{BC}$, in particular the M phase (48). Whether miR-126-3p overexpression affects apoptosis and the cell cycle in TNBC as well as whether a combination treatment with miR-126-3p affects TNBC cell function are our next goals in future research.

RGS3 was predicted to be a potential target of miR-126-3p by TargetScan algorithm due to their complementary binding which was further validated through a luciferase activity reporter assay. Notably, it was revealed that targeting and combination of transfected exogenous RGS3, which lacks the 3 'UTR region for miR-126-3p, could revert the inhibitory effects of miR-126-3p on TNBC cell behaviors, indicating that RGS3 was directly involved in miR-126-3p-induced inhibition of cell behaviors.

$\mathrm{VM}$ is important for disease progression of many aggressive tumors such as hepatocellular carcinoma, as well as prostate, ovarian and lung cancer (49-52). VM has been reported to be related to the metastasis and poor prognosis of TNBC (24,53-54). The present study revealed that angiogenesis could be induced by miR-126-3p silencing and suppressed by miR-126-3p overexpression, while it was promoted by overexpression of RGS3 and inhibited by RGS3 silencing. Moreover, the overexpression of RGS3 could recover the inhibitory effect of miR-126-3p on VM of TNBC cells, indicating that RGS3 directly contributed to miR-126-3p-induced VM inhibition processes which provides a new target for anti-angiogenesis therapy. Therefore, it was deduced that miR-126-3p/RGS3 has the potential to be a new biomarker for TNBC treatment.

Collectively, the tumor suppressive role of the miR-126-3p/RGS3 axis on cell proliferation, colony formation, migration, invasion, and VM in TNBC was verified, which may be a potential target for cancer therapy treatment.

\section{Acknowledgements}

Not applicable.

\section{Funding}

The present research was supported by the Youth Scientific Research Project of Fujian Provincial Health and Family Planning Commission, PRC (no. 2016-1-91).

\section{Availability of data and materials}

The datasets used and/or analyzed during the current study are available from the corresponding author on reasonable request.

\section{Authors' contributions}

$\mathrm{ZH}$ performed the majority of the study and wrote the manuscript. $\mathrm{CH}$ conducted the vasculogenic mimicry formation assays and data analysis and BM performed the dual luciferase activity assay and data analysis. QW, XZ and LL helped with the cell function assays and data analysis. CW and DC designed the experiments and edited the manuscript. All authors read and approved the final manuscript and agree to be accountable for all aspects of the research in ensuring that the accuracy or integrity of any part of the work are appropriately investigated and resolved.

\section{Ethics approval and consent to participate}

Not applicable.

\section{Patient consent for publication}

Not applicable.

\section{Competing interests}

The authors declare that they have no competing interests.

\section{References}

1. Siegel RL, Miller KD and Jemal A: Cancer statistics, 2017. CA Cancer J Clin 67: 7-30, 2017.

2. Bray F, Ferlay J, Soerjomataram I, Siegel RL, Torre LA and Jemal A: Global Cancer statistics 2018: GLOBOCAN estimates of incidence and mortality worldwide for 36 cancers in 185 countries. CA Cancer J Clin 68: 394-424, 2018.

3. Yuan N, Meng M, Liu C, Feng L, Hou L, Ning Q, Xin G, Pei L, $\mathrm{Gu}$ S, Li X and Zhao X: Clinical characteristics and prognostic analysis of triple-negative breast cancer patients. Mol Clin Oncol 2: 245-251, 2014.

4. Lehmann BD, Bauer JA, Chen X, Sanders ME, Chakravarthy AB, Shyr Y and Pietenpol JA: Identification of human triple-negative breast cancer subtypes and preclinical models for selection of targeted therapies. J Clin Invest 121: 2750-2767, 2011.

5. Gerratana L, Fanotto V, Bonotto M, Bolzonello S, Minisini AM, Fasola G and Puglisi F: Pattern of metastasis and outcome in patients with breast cancer. Clin Exp Metastasis 32: 125-133, 2015. 
6. Tsai CH, Chiu JH, Yang CW, Wang JY, Tsai YF, Tseng LM, Chen WS and Shyr YM: Molecular characteristics of recurrent triple-negative breast cancer. Mol Med Rep 12: 7326-7334, 2015.

7. M Braden A, V Stankowski R, M Engel J and A Onitilo A: Breast cancer biomarkers: Risk assessment, diagnosis, prognosis, prediction of treatment efficacy and toxicity, and recurrence. Curr Pharm Des 20: 4879-4898, 2014.

8. Yang C, Hou C, Zhang H, Wang D, Ma Y, Zhang Y, Xu X, Bi Z and Geng S: miR-126 functions as a tumor suppressor in osteosarcoma by targeting Sox2. Int J Mol Sci 15: 423-437, 2013.

9. Jones KB, Salah Z, Del Mare S, Galasso M, Gaudio E, Nuovo GJ, Lovat F, LeBlanc K, Palatini J, Randall RL, et al: miRNA signatures associate with pathogenesis and progression of osteosarcoma. Cancer Res 72: 1865-1877, 2012.

10. Najafi Z, Sharifi M and Javadi G: Degradation of miR-21 induces apoptosis and inhibits cell proliferation in human hepatocellular carcinoma. Cancer Gene Ther 22: 530-535, 2015.

11. Sandhu R, Rivenbark AG, Mackler RM, Livasy CA and Coleman WB: Dysregulation of microRNA expression drives aberrant DNA hypermethylation in basal-like breast cancer. Int J Oncol 44: 563-572, 2014.

12. Zhu X, Li H, Long L, Hui L, Chen H, Wang X, Shen H and Xu W: miR-126 enhances the sensitivity of non-small cell lung cancer cells to anticancer agents by targeting vascular endothelial growth factor A. Acta Biochim Biophys Sin (Shanghai) 44: 519-526, 2012

13. Yu Q, Liu SL, Wang H, Shi G, Yang P and Chen X: miR-126 suppresses the proliferation of cervical cancer cells and alters cell sensitivity to the chemotherapeutic drug bleomycin. Asian Pac J Cancer Prev 14: 6569-6572, 2014

14. Akao Y, Noguchi S, Iio A, Kojima K, Takagi $T$ and Naoe T: Dysregulation of microRNA-34a expression causes drug-resistance to 5-FU in human colon cancer DLD-1 cells. Cancer Lett 300: 197-204, 2011.

15. Kuhnert F, Mancuso MR, Hampton J, Stankunas K, Asano T, Chen C and Kuo CJ: Attribution of vascular phenotypes of the murine Egfl7 locus to the microRNA miR-126. Development 135: 3989-3993, 2008.

16. Liu W, Zhao ZY, Shi L and Yuan WD: Tissue microRNA-126 expression level predicts outcome in human osteosarcoma. Diagn Pathol 10: 116, 2015.

17. Hansen TF, Nielsen BS, Jakobsen A and Sørensen FB: Intra-tumoural vessel area estimated by expression of epidermal growth factor-like domain 7 and microRNA-126 in primary tumours and metastases of patients with colorectal cancer: A descriptive study. J Transl Med 13: 10, 2015.

18. Fujii T, Shimada K, Tatsumi Y, Fujimoto K and Konishi N: Syndecan-1 responsive microRNA-126 and 149 regulate cell proliferation in prostate cancer. Biochem Biophys Res Commun 456: 183-189, 2015

19. Liu LY, Wang W, Zhao LY, Guo B, Yang J, Zhao XG, Hou N, Ni L, Wang AY, Song TS, et al: MiR-126 inhibits growth of SGC-7901 cells by synergistically targeting the oncogenes PI3KR 2 and Crk, and the tumor suppressor PLK2. Int J Oncol 45: 1257-1265, 2014

20. Yanaihara N, Caplen N, Bowman E, Seike M, Kumamoto K, Yi M, Stephens RM, Okamoto A, Yokota J, Tanaka T, et al: Unique microRNA molecular profiles in lung cancer diagnosis and prognosis. Cancer Cell 9: 189-198, 2006.

21. Maniotis AJ, Folberg R, Hess A, Seftor EA, Gardner LM, Pe'er J, Trent JM, Meltzer PS and Hendrix MJ: Vascular channel formation by human melanoma cells in vivo and in vitro: Vasculogenic mimicry. Am J Pathol 155: 739-752, 1999.

22. Kirschmann DA, Seftor EA, Hardy KM, Seftor RE and Hendrix MJ: Molecular pathways: Vasculogenic mimicry in tumor cells: Diagnostic and therapeutic implications. Clin Cancer Res 18: 2726-2732, 2012

23. Meister J and Schmidt MHH: miR-126 and miR-126*: New players in cancer. ScientificWorldJournal 10: 2090-2100, 2010.

24. Liu T, Sun B, Zhao X, Li Y, Gu Q, Dong X and Liu F: OCT4 expression and vasculogenic mimicry formation positively correlate with poor prognosis in human breast cancer. Int J Mol Sci 15: 19634-19649, 2014.

25. Liu T, Sun B, Zhao X, Gu Q, Dong X, Yao Z, Zhao N, Chi J, Liu N, Sun R and Ma Y: HER2/neu expression correlates with vasculogenic mimicry in invasive breast carcinoma. J Cell Mol Med 17: 116-122, 2013.

26. Shirakawa K, Kobayashi H, Sobajima J, Hashimoto D, Shimizu A and Wakasugi H: Inflammatory breast cancer: Vasculogenic mimicry and its hemodynamics of an inflammatory breast cancer xenograft model. Breast Cancer Res 5: 136-139, 2003.
27. Dulin NO, Pratt P, Tiruppathi C, Niu J, Voyno-Yasenetskaya T and Dunn MJ: Regulator of G protein signaling RGS3T is localized to the nucleus and induces apoptosis. J Biol Chem 275: 21317-21323, 2000

28. Eusemann TN, Willmroth F, Fiebich B, Biber K and van Calker D: Adenosine receptors differentially regulate the expression of regulators of G-protein signalling (RGS) 2, 3 and 4 in astrocyte-like cells. PLoS One 10: e0134934, 2015.

29. Sethakorn N and Dulin NO: RGS expression in cancer: Oncomining the cancer microarray data. J Recept Signal Transduct Res 33: 166-171, 2013.

30. Tatenhorst L, Senner V, Püttmann S and Paulus W: Regulators of G-protein signaling 3 and 4 (RGS3, RGS4) are associated with glioma cell motility. J Neuropathol Exp Neurol 63: 210-222, 2004 .

31. Feng R, Chen X, Yu Y, Su L, Yu B, Li J, Cai Q, Yan M, Liu B and Zhu Z: miR-126 functions as a tumour suppressor in human gastric cancer. Cancer Lett 298: 50-63, 2010.

32. Wang J, Chen X, Li P, Su L, Yu B, Cai Q, Li J, Yu Y, Liu B and Zhu Z: CRKL promotes cell proliferation in gastric cancer and is negatively regulated by miR-126. Chem Biol Interact 206 : 230-238, 2013

33. Wang J,Zhou Y,Fei X, Chen X and Zhu Z: Regulator of G-protein signaling 3 targeted by miR-126 correlates with poor prognosis in gastric cancer patients. Anticancer Drugs 28: 161-169, 2017.

34. Livak KJ and Schmittgen TD: Analysis of relative gene expression data using real-time quantitative PCR and the 2(-Delta Delta C(T)) method. Methods 25: 402-408, 2001

35. Piasecka D, Braun M, Kordek R, Sadej R and Romanska H: MicroRNAs in regulation of triple-negative breast cancer progression. J Cancer Res Clin Oncol 144: 1401-1411, 2018.

36. Zhang L, Xu Y, Jin X, Wang Z, Wu Y, Zhao D, Chen G, Li D, Wang $\mathrm{X}$, Cao $\mathrm{H}$, et al: A circulating miRNA signature as a diagnostic biomarker for non-invasive early detection of breast cancer. Breast Cancer Res Treat 154: 423-434, 2015.

37. Wang B, Li J, Sun M, Sun L and Zhang X: miRNA expression in breast cancer varies with lymph node metastasis and other clinicopathologic features. IUBMB Life 66: 371-377, 2014

38. Gomes BC, Martins M, Lopes P, Morujão I, Oliveira M, Araújo A, Rueff J and Rodrigues AS: Prognostic value of microRNA-203a expression in breast cancer. Oncol Rep 36: 1748-1756, 2016

39. Wang Y, Zhang Z and Wang J: MicroRNA-384 inhibits the progression of breast cancer by targeting ACVR1. Oncol Rep 39: 2563-2574, 2018

40. Zhang HD, Jiang LH, Hou JC, Zhou SY, Zhong SL, Zhu LP Wang DD, Yang SJ, He YJ, Mao CF, et al: Circular RNA has_circ_0072995 promotes breast cancer cell migration and invasion through sponge for miR-30c-2-3p. Epigenomics 10: $1229-1242,2018$

41. Paszek S, Gabło N, Barnaś E, Szybka M, Morawiec J, Kołacińska A and Zawlik I: Dysregulation of microRNAs in triple-negative breast cancer. Ginekol Pol 88: 530-536, 2017.

42. Otsubo T, Akiyama Y, Hashimoto Y, Shimada S, Goto K and Yuasa Y: MicroRNA-126 inhibits SOX2 expression and contributes to gastric carcinogenesis. PLoS One 6: e16617, 2011.

43. Guo C, Sah JF, Beard L, Willson JK, Markowitz SD and Guda K: The noncoding RNA, miR-126, suppresses the growth of neoplastic cells by targeting phosphatidylinositol 3-kinase signaling and is frequently lost in colon cancers. Genes Chromosomes Cancer 47: 939-946, 2008.

44. Zhang J, Du YY, Lin YF, Chen YT, Yang L, Wang HJ and Ma D: The cell growth suppressor, miR-126, targets IRS-1. Biochem Biophys Res Commun 377: 136-140, 2008.

45. Chang YY, Kuo WH, Hung JH, Lee CY, Lee YH, Chang YC, Lin WC, Shen CY, Huang CS, Hseih FJ, et al: Deregulated microRNAs in triple-negative breast cancer revealed by deep sequencing. Mol Cancer 14: 36, 2015.

46. Liu Y, Cai Q, Bao PP, Su Y, Cai H, Wu J, Ye F, Guo X, Zheng W, Zheng Y and Shu XO: Tumor tissue microRNA expression in association with triple-negative breast cancer outcomes. Breast Cancer Res Treat 152: 183-191, 2015.

47. Turashvili G, Lightbody ED, Tyryshkin K, SenGupta SK, Elliott BE, Madarnas Y, Ghaffari A, Day A and Nicol CJB: Novel prognostic and predictive microRNA targets for triple-negative breast cancer. FASEB J 29: fj201800120R, 2018

48. Baldassari F, Zerbinati C, Galasso M, Corrà F, Minotti L, Agnoletto C, Previati M, Croce CM and Volinia S: Screen for microRNA and drug interactions in breast cancer cell lines points to miR-126 as a modulator of CDK4/6 and PIK3CA inhibitors. Front Genet 9: 174, 2018 
49. Sun T, Zhao N, Zhao XL, Gu Q, Zhang SW, Che N, Wang XH, Du J, Liu YX and Sun BC: Expression and functional significance of Twist1 in hepatocellular carcinoma: Its role in vasculogenic mimicry. Hepatology 51: 545-556, 2010.

50. Liu R, Yang K, Meng C, Zhang Z and Xu Y: Vasculogenic mimicry is a marker of poor prognosis in prostate cancer. Cancer Biol Ther 13: 527-533, 2012.

51. Wang JY, Sun T, Zhao XL, Zhang SW, Zhang DF, Gu Q, Wang XH, Zhao N, Qie S and Sun BC: Functional significance of VEGF-a in human ovarian carcinoma: Role in vasculogenic mimicry. Cancer Biol Ther 7: 758-766, 2008.

52. Li Y, Sun B, Zhao X, Zhang D, Wang X, Zhu D, Yang Z, Qiu Z and Ban X: Subpopulations of uPAR+ contribute to vasculogenic mimicry and metastasis in large cell lung cancer. Exp Mol Pathol 98: 136-144, 2015.
53. Zhang D, Sun B, Zhao X, Ma Y, Ji R, Gu Q, Dong X, Li J, Liu F, Jia $X$, et al: Twist1 expression induced by sunitinib accelerates tumor cell vasculogenic mimicry by increasing the population of CD133+ cells in triple-negative breast cancer. Mol Cancer 13: 207, 2014.

54. Wagenblast E, Soto M, Gutiérrez-Ángel S, Hartl CA, Gable AL, Maceli AR, Erard N, Williams AM, Kim SY, Dickopf S, et al: A model of breast cancer heterogeneity reveals vascular mimicry as a driver of metastasis. Nature 520: 358-362, 2015. 